\title{
UJI EFEK ANTIPIRETIK EKSTRAK DAUN PEPAYA (Carica papaya L.) PADA TIKUS WISTAR (Rattus norvegicus)
}

\author{
${ }^{1}$ Seila Apriliani Yapian \\ ${ }^{2}$ Robert Bara \\ ${ }^{2}$ Henoch Awaloei \\ ${ }^{2}$ Jane Wuisan
}

\author{
${ }^{1}$ Kandidat Skripsi Fakultas Kedokteran Universitas Sam Ratulangi Manado \\ ${ }^{2}$ Bagian Farmakologi dan Terapi Fakultas Kedokteran Universitas Sam Ratulangi \\ Email: seilayapian10_011@yahoo.com
}

\begin{abstract}
The aim of this study is to investigate the effect of papaya leaves extract (Carica papaya) on rectal temperature drop of Wistar rats (Rattus norvegicus) by using fever induction method. Method:15 Wistar rats is divided into 5 groups, each consisting of 3 rats. Negative control group was given aquadest, the positive control group was given paracetamol and 3 intervention groups were given papaya leaves extract each with a dose of 50, 100 and 200mg body weight of rats. Fever is induced in test animals using DPT-HB vaccine 0,3ml. Rectal temperature measurements are taken before and after the administration of vaccine and after the administration of the test substance at 30, 60, 90 and 120 minute consecutively. Result: Administration of papaya leaves extract at a doseof $200 \mathrm{mg} / \mathrm{kg}$ body weight showed greater rectal temperature drop effect compared to 100 and $50 \mathrm{mg} / \mathrm{kg}$ body weight dose. Administration of paracetamol showed a greater rectal temperature drop compared to the $200 \mathrm{mg} / \mathrm{kg}$ body weight dose of papaya leaves extract. Conclusion: Papaya leaf extract showed antipyretic effects in Wistar rats, but has lower antipyretic effect compared to paracetamol..
\end{abstract}

Keywords:antipyretic, papaya leaf, DPT-HB, Wistar rat

\begin{abstract}
Abstrak: Penelitian ini bertujuan untuk mengetahui adanya pengaruh pemberian ekstrak daun pepaya (Carica papaya) terhadap penurunan suhu rektal tikus Wistar (Rattus norvegicus) dengan menggunakan metode induksi demam. Metode:Hewan uji yang digunakan berupa 15 ekor tikus Wistar yang dibagi ke dalam 5 kelompok, masing-masing kelompok terdiri dari 3 ekor tikus. Kelompok kontrol negatif diberikan aquades, kelompok kontrol positif diberikan parasetamol, dan 3 kelompok eksperimental diberikan ekstrak daun pepaya masing-masing dengan dosis 50, 100 dan 200mg/kgBB tikus. Induksi demam pada hewan uji menggunakan vaksin DPT-HB 0,3ml. Pengukuran suhu rektal dilakukan sebelum dan sesudah pemberian vaksin dan setelah pemberian zat uji berturut-turut pada menit ke-30, 60, 90 dan 120. Hasil: Pemberian ekstrak daun pepaya dengan dosis $200 \mathrm{mg} / \mathrm{kgBB}$ menunjukkan penurunan suhu rektal lebih besar dibanding dengan dosis 100 dan 50mg/kgBB. Pemberian parasetamol menunjukkan penurunan suhu rektal lebih tinggi dibanding dengan dosis ekstrak 200mg/kgBB.Kesimpulan: Ekstrak daun pepaya menunjukkan adanya efek antipiretik pada tikus Wistar namun efek antipiretiknya lebih rendah dari parasetamol.
\end{abstract}

Kata Kunci: antipiretik, daun pepaya, DPT-HB, tikus Wistar 
Indonesia memiliki berbagai macam kekayaan alam, di antaranya ialah kekayaan tumbuh-tumbuhan yang termasuk di dalamnya tanaman berkhasiat obat. Pemanfaatan tanaman berkhasiat obat sudah lama dilakukan oleh masyarakat dan diwariskan secara turun-temurun ke generasi berikutnya sebagai obat tradisional. ${ }^{1}$ Berdasarkan data pada Lokakarya Nasional Tanaman Obat tahun 2010, Indonesia memiliki 30.000 jenis tumbuhan dari total 40.000 jenis tumbuhan di dunia, termasuk di antaranya 940 jenis tumbuhan berkhasiat obat. ${ }^{2}$

Pepaya (Carica papaya L.) merupakan salah satu tanaman berkhasiat obat. Salah satu bagian dari tanaman pepaya yang berkhasiat obat ialah daunnya. Daun pepaya sering dijadikan bahan makanan sehari-hari walaupun rasanya pahit. Khasiat daun pepaya diyakini masyarakat bisa mengatasi demam, keputihan, jerawat, menambah nafsu makan, menambah air susu ibu, dan mengobati sakit gigi. Daun pepaya mengandung senyawa alkaloid, enzim papain, flavonoid, glikosid, karposid, sakarosa, dekstrosa, levulosa, benzilgluko-sinolat dan tannin. ${ }^{3-7}$

Demam adalah peningkatan suhu tubuh di atas batas normal. Suhu normal tubuh berkisar antara $36,5-37,5^{\circ} \mathrm{C}$. Demam pada anak dapat membuat orang tua cemas, mengingat bisa terjadi komplikasi kejang demam. Hal inilah yang mendorong para orang tua membawa anaknya ke rumah sakit untuk mendapatkan pengobatan. Untuk masyarakat yang tinggal di pedesaan yang jasa pelayanan kesehatan masih minim, demam diatasi dengan cara pengobatan tradisional. ${ }^{8-11}$

Masyarakat di daerah Minahasa dan Kotamobagu, masih banyak menggunakan pengobatan tradisional untuk mengatasi masalah kesehatan. Salah satunya menggunakan daun pepaya sebagai obat penurun demam. Caranya dengan merebus daun pepaya kemudian meminum air rebusan tersebut.

\section{Bahan dan Metode}

Jenis penelitian ini bersifat eksperimental yang dilakukan di Laboratorium Farmakologi dan Terapi Fakultas Kedokteran Universitas Sam Ratulangi (UNSRAT) Manado.

\section{Pengambilan Bahan}

Daun pepaya yang digunakan yaitu daun pepaya muda yang masih segar diambil dari Desa Matungkas Kecamatan Dimembe Kabupaten Minahasa Utara.

\section{Ekstrak Daun Pepaya}

Daun pepaya dikeringkan dalam oven dengan suhu $40^{\circ} \mathrm{C}$. Daun pepaya kering diblender sehingga didapatkan serbuk daun pepaya. Serbuk daun pepaya $100 \mathrm{~g}$ direndam dengan etanol $70 \%$ sebanyak $500 \mathrm{ml}$ selama \pm 5 hari (15 menit pengadukan setiap hari). Filtrat yang didapat diuapkan dengan evaporator lalu dimasukkan dalam oven dengan suhu $40^{\circ} \mathrm{C}$. Ekstrak yang dihasilkan berupa ekstrak kental yang digunakan dalam penelitian. 


\section{Hewan Uji}

Hewan uji yang digunakan pada penelitian ini adalah 15 ekor tikus Wistar jantan dengan berat sekitar 150 gram yang dibagi menjadi 5 kelompok, masing- masing kelompok terdiri dari 3 ekor tikus. Semua hewan uji dipuasakan \pm 8 jam sebelum diberikan perlakuan. Masing-masing hewan uji akan diinduksi demam menggunakan vaksin DPT-HB.

Kelompok I sebagai kontrol negatif yang diberi aquades $1 \mathrm{ml}$, kelompok II sebagai kontrol positif diberi parasetamol 6,4mg/150kgBB tikus, kelompok III, IV, V diberi ekstrak daun pepaya dengan dosis 50, 100 dan 200 mg/kgBB.

\section{Pengujian Efek Antipiretik Ekstrak Daun Pepaya}

Tikus Wistar telah diadaptasikan selama 1 minggu dan dipuasakn selama \pm 8 jam sebelum perlakuan. Semua hewan uji diukur suhu rektal awal sebelum penyuntikan vaksin DPT-HB. Hewan uji disuntik vaksin DPT-HB 0,3ml secara intramuskular untuk menginduksi terjadinya demam. Peningkatan suhu tubuh diukur secara rektal 3 jam setelah penyuntikan vaksin. Setelah itu kelompok kontrol negatif diberi aquades, kontrol positif diberi parasetamol dan kelompok perlakuan diberi ekstrak daun pepaya 50, 100 dan 200mg/kgBB secara oral dengan menggunakan Nasogastric tube (NGT) no.5. Untuk melihat efek dari masing-masing perlakuan, dilakukan pengukuran suhu rektal tiap 30 menit sampai menit ke-120 dengan menggunakan termometer digital.

\section{Hasil}

Hasil pengukuran suhu rektal rata-rata sebelum dan sesudah penyuntikan vaksin serta suhu rektal setelah perlakuan dapat dilihat pada Tabel 1 dan Gambar 1 berikut ini.

Tabel 1. Hasil Pengukuran Suhu Rektal Tikus Wistar Sebelum dan Sesudah Perlakuan

\begin{tabular}{ccccccc}
\hline & \multicolumn{6}{c}{ Suhu Rektal $\left({ }^{\circ} \mathrm{C}\right)$} \\
\cline { 2 - 7 } Kelompok & \multicolumn{5}{c}{ Sebelum Perlakuan } & \multicolumn{4}{c}{ Setelah Perlakuan } \\
\cline { 2 - 7 } & $\mathrm{t}_{\mathrm{a}}$ & $\mathrm{t}_{0}$ & $30^{\prime}$ & $60^{\prime}$ & 90 & 120 \\
\hline Aquades & 37,2 & 38,1 & 38,3 & 38,3 & 38,5 & 38,4 \\
Parasetamol & 37,1 & 38,4 & 38,4 & 38,3 & 37,9 & 37,7 \\
Dosis 1 & 37,3 & 38,4 & 38,5 & 38,6 & 38,4 & 38,4 \\
Dosis 2 & 37,3 & 38,1 & 38,3 & 38,4 & 38,3 & 38,3 \\
Dosis 3 & 37,4 & 38,1 & 38,3 & 38,5 & 38,2 & 38,0 \\
\hline
\end{tabular}

Ket:

$\mathrm{t}_{\mathrm{a}}=$ suhu rektal sebelum penyuntikan vaksin DPT-HB

$\mathrm{t}_{0}=$ suhu rektal 3 jam setelah penyuntikan vaksin DPT-HB 


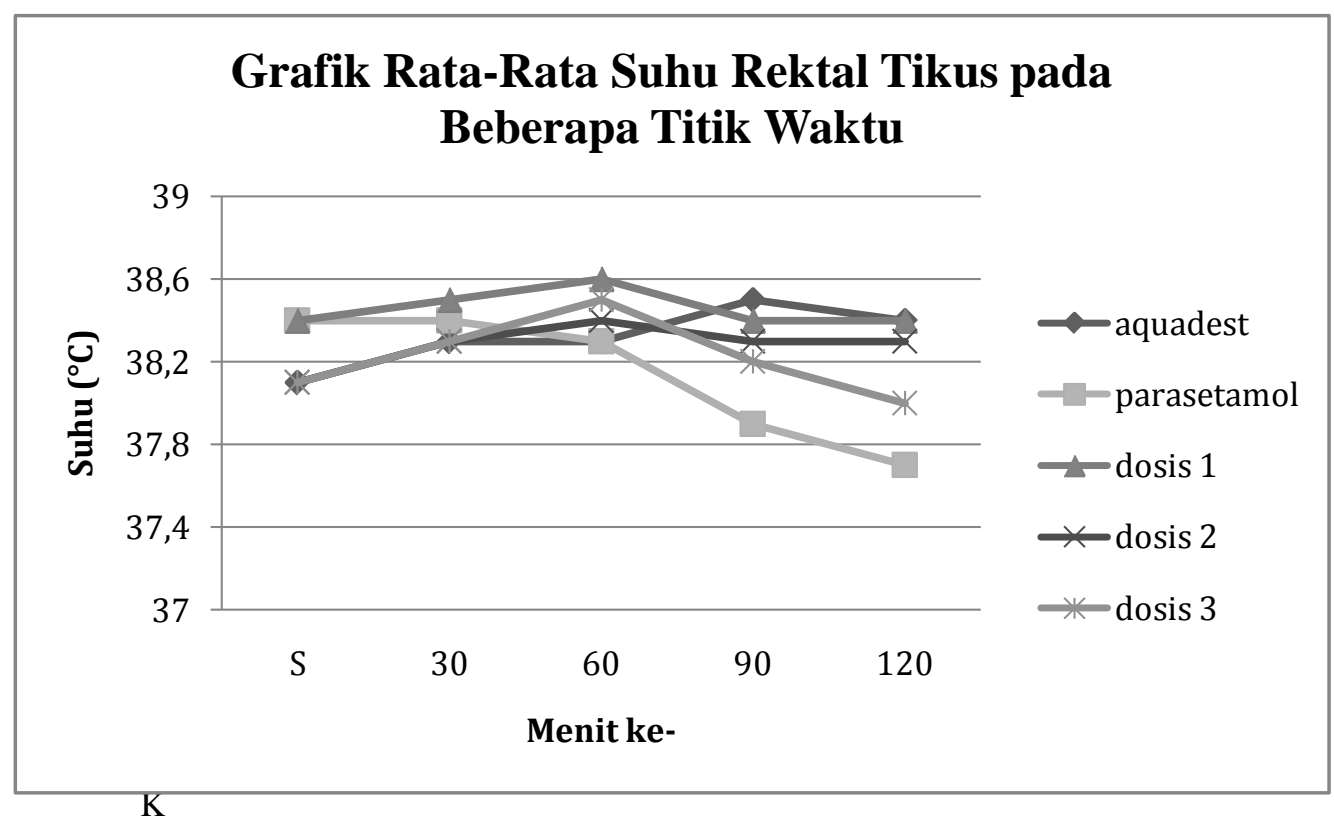

Ket: $\mathrm{S}=$ suhu rektal sebelum perlakuan

Gambar 1. Grafik Rata-Rata Suhu Rektal Tikus pada Beberapa Titik Waktu

\section{Pembahasan}

Pemberian ekstrak daun pepaya dengan dosis 50mg/kgBB dan 100mg/kgBB dalam waktu 2 jam penelitian belum menunjukkan adanya perbedaan penurunan suhu rektal dibandingkan dengan kontrol negatif, karena penurunan suhu hanya berkisar $0,1^{\circ} \mathrm{C}$. Diduga dosis 50 dan $100 \mathrm{mg} / \mathrm{kgBB}$ belum memberikan efek antipiretik yang diharapkan dalam rentang waktu 2 jam penelitian.

Pemberian ekstrak daun pepaya dengan dosis 200mg/kgBB menunjukkan penurunan suhu rektal $0,4^{\circ} \mathrm{C}$ dibandingkan kontrol negatif pada menit ke- 120 . Perbedaan suhu rektal sekitar $0,3-0,4^{\circ} \mathrm{C}$ dibandingkan dengan dosis 50 dan $100 \mathrm{mg} / \mathrm{kgBB}$. Kemungkinan ekstrak daun pepaya dengan dosis 200mg/kgBB dapat memberikan penurunan suhu rektal yang lebih besar apabila rentang waktu penelitian dilakukan lebih dari 2 jam.

Pada kelompok kontrol positif setelah penyuntikan vaksin, suhu rektal meningkat dan setelah pemberian parasetamol suhu rektal mulai menurun dalam rentang menit ke-60 sampai 120. Penurunan suhu rektal pada pemberian parasetamol lebih besar dibandingkan dengan kelompok yang diberi dosis ekstrak daun pepaya 50, 100 dan 200mg/kgBB.

Berdasarkan hasil penelitian yang didapat, efek antipiretik dari ekstrak daun pepaya ini diduga karena adanya senyawa flavonoid yang terkandung dalam daun pepaya. Hasil penelitian Adesokan tahun 2008 membuktikan bahwa flavonoid dapat bersifat antipiretik. ${ }^{15}$ Selain flavonoid, efek antipiretik dari daun pepaya juga mungkin disebabkan oleh kandungan kimia lainnya. Oleh karena itu, perlu dilakukan penelitian lebih lanjut mengenai kandungan kimia lain yang berperan sebagai antipiretik beserta mekanisme kerjanya. 


\section{Kesimpulan dan Saran}

Berdasarkan hasil uji efek antipiretik ekstrak daun pepaya pada tikus Wistar yang diamati selama 120 menit, dapat disimpulkan bahwa ekstrak daun pepaya dengan dosis 200mg/kgBB dapat memberikan efek antipiretik pada tikus Wistar, namun efek antipiretiknya lebih rendah dibandingkan dengan parasetamol.

Perlu dilakukan penelitian lanjut untuk identifikasi senyawa yang berkhasiat antipiretik pada daun pepaya beserta mekanismenya. Penelitian dengan dosis yang lebih tinggi dan waktu penelitian yang lebih panjang juga perlu dilakukan serta penelitian lanjutan uji efek antipiretik ekstrak daun pepaya dibandingkan dengan obat antipiretik lain.

\section{Daftar Pustaka}

1. Rahmawati U, Suryani E, Mukhlason A. Pengembangan Repository Pengetahuan Berbasis Ontologi (Ontology-Driven Knowledge Repository) Untuk Tanaman Obat Indonesia. Jurnal Teknik Pomits. 2012;1(1):1-6.

2. Nugroho IA. Lokakarya Nasional Tanaman Obat Indonesia [internet]. 2010. Diunduh

dari: http://forplan.or.id/images/File/Apforgen/Newsletter/2010/LTOI\%20dan\%20 Merbau\%20PER\%20HAL.pdf . Diakses 11 Oktober 2013.

3. Yahya M. Pepaya. Dalam: Novieta N,editor. Khasiat Daun Pepaya Untuk Penderita Kanker. Jakarta: Dunia Sehat; 2012. h. 49-60.

4. Mardiana L. Daun Ajaib Tumpas Penyakit. Jakarta: Penebar Swadaya; 2012. h. 115-9.

5. Redaksi AgroMedia Pustaka. Buku Pintar Budi Daya Tanaman Buah Unggul Indonesia. Jakarta: AgroMedia Pustaka; 2009. h. 191. Diunduh dari: http://books.google.co.id/books?id=FAskAIxMHI0C. Diakses 11 September 2013.

6. Rehena JF. Uji Aktivitas Ekstrak Daun Pepaya (Carica papaya. LINN) sebagai Antimalaria in vitro. Jurnal Ilmu Dasar. 2010;11(1):96-100.

7. Risandi Y, Emriadi, Stiadi Y. Ekstrak Daun Pepaya (Carica papaya) Sebagai Inhibitor Korosi Baja St.37 Dalam Medium Asam Sulfat. Jurnal Kimia Unand. 2012;1(1):27.

8. Guyton AC, Hall JE. Suhu Tubuh, Pengaturan Suhu dan Demam. Dalam: Rachman LY, Hartanto H, Novrianti A, Wulandari N, editor. Buku Ajar Fisiologi Kedokteran. Edisi ke-11. Jakarta: EGC;2007. h. 945-6.

9. Ganong WF. Pengaturan Sentral Fungsi Visera. Dalam: Novrianti A, Dany F, Resmisari T, Rachman LY, Muttaqin H, Nugroho AW, Rendy L, Liena, Dwijayanthi L, Bourman V, editor. Buku Ajar Fisiologi Kedokteran. Edisi ke-22. Jakarta: EGC; 2008. h. 266-8.

10. Anochie, Ifesinachi P. Mechanisms of Fever In Humans. International Journal of Microbiology and Immunology Research. 2013;2(5):037-043.

11. Soedibyo S, Souvriyanti E. Gambaran Persepsi Orang Tua Tentang Penggunaan Antipiretik Sebagai Obat Demam. Sari Pediatri 2006;8(2):142-6.

12. Adesokan AA, Yakubu MT, Owoyele BV, Akanji MA, Soladoye AO, Lawal O. Effect of Administration of Aqueous and Ethanol Extracts of Enantia chlorantha Stem Bark on Brewer's Yeast Induced Pyresis in Rats. African J of Biochemistry 2008;2(7):165-9. 
